\title{
Los catalanes en la ciudad de México. Las festividades de Montserrat y Sant Jordi (1887-1908)
}

\author{
Catalans in Mexico City. \\ The Montserrat and Sant Jordi \\ Festivities (1887-1908)
}

\author{
María del Mar Gutiérrez Domínguez \\ (D) https://orcid.org/0000-0001-6020-2307 \\ El Colegio de México, México \\ margutierrezdominguez@gmail.com
}

Resumen: Este artículo analiza la presencia catalana en la ciudad de México a fines del siglo xIx y comienzos del xx, por medio de dos festividades: la de la Virgen de Montserrat y la de Sant Jordi. La investigación se centra en el perfil social de los catalanes que participaron en estos festejos, así como en la articulación de la identidad catalana por los individuos de este origen residentes en la capital de México. Asimismo, se atiende la relación del grupo de catalanes con el conjunto de la inmigración española, cuya parte más visible se reunía en el Casino Español. Todo lo anterior se dio en un contexto de fortalecimiento de las relaciones internacionales entre México y España, cuando México experimentaba su transición hacia una economía capitalista y al tiempo que Cataluña se erigía en referente de la España industrial.

Palabras clave: catalanes; México; Montserrat; Sant Jordi; Orfeó Català.

cómo citar: Gutiérrez Domínguez, M. del. M. (2022). Los catalanes en la ciudad de México. Las festividades de Montserrat y Sant Jordi (1887-1908). Secuencia (112), e1837. Dor: https://doi.org/10.18234/ secuencia.v0i112.1837

c) 98

Esta obra está protegida bajo una Licencia Creative Commons Atribución-NoComercial 4.0 Internacional. 
Abstract: The article analyzes Catalan presence in Mexico City at the end of the 19th and the beginning of the 20th century, through two festivities: that of the Virgin of Montserrat and Sant Jordi. The research focuses on the social profile of the Catalans who participated in these festivities, as well as the construction of Catalan identity by people of this origin residing in the capital of Mexico. Likewise, the relationship between the Catalan group and Spanish immigration is addressed, the most visible part of which met in the Casino Español. All the above took place in a context of strengthening international relations between Mexico and Spain when Mexico was transitioning towards a capitalist economy while Catalonia was emerging as a benchmark for industrial Spain.

Keywords: Catalan; Mexico; Montserrat; Sant Jordi; Orfeó Català.

Recibido: 1 de marzo de 2020 Aceptado: 3 de septiembre de 2020

Publicado: 25 de enero de 2022

E lobjetivo de este artículo es el análisis de la presencia catalana en la ciudad de México a finales del siglo xix y comienzos del xx. Por un lado, se trata de estudiar al grupo de individuos perteneciente a esta colectividad extranjera que tuvieron presencia y visibilidad en las instituciones comunitarias, por otro, analizar la construcción de "lo catalán" por parte de la emigración de este origen en la capital del país. La investigación se centra en dos momentos de la vida interna de los catalanes en la ciudad de México: la celebración de la fiesta de Montserrat, entre 1887 y 1892, y la fundación del Orfeó Català,

${ }^{1}$ Para esta investigación se han considerado como "catalanes" en la ciudad de México a los individuos procedentes de la región de Cataluña que emigraron a la capital mexicana a lo largo del periodo en estudio. También se identifican como "catalanes" a los descendientes de estos emigrantes, quienes constituirían una segunda generación. Aunque nacidos en México, muchos de ellos optaron a los 18 años por la nacionalidad paterna (española), y en tanto descendientes de inmigrantes catalanes participaron en las fiestas y la sociabilidad catalana en México. Muchos de estos inmigrantes hablaban el idioma catalán; sin embargo, en este artículo se da prioridad al origen regional por sobre el habla de la lengua catalana, de tal manera que si un inmigrante procedía de Cataluña - pero no hablaba el idioma catalán- se le ha identificado igualmente como "catalán". Cabe señalar que en este artículo la identificación de los individuos "catalanes" ha sido posible realizarla en función de su participación en una sociabilidad de carácter regional -catalán-, lo que constituye una de las limitaciones del presente estudio. Esto es, no dudo que existieran más catalanes en México que aquellos que estuvieron interesados en desarrollar una sociabilidad con base en la identidad regional. 
en 1906. Esta última institución inauguró la celebración de la fiesta de Sant Jordi en la capital del país, la cual volvió a reunir a los catalanes en torno a una festividad propia que, a la altura de 1908, tenía varios significados, enfrentados entre sí. Los eventos y festejos anteriores se enmarcan en un contexto de fortalecimiento de las relaciones internacionales entre México y España, que puso especial interés en propiciar el intercambio del comercio bilateral, al tiempo que México favorecía la entrada de capitales -nacionales y extranjeros- para el impulso de una industria propia. ${ }^{2}$ A este respecto, cabe señalar que Cataluña era -junto con el País Vasco- la región más industrializada de España y que un número no desdeñable de los inmigrantes de este origen se desempeñaron como empresarios fabriles en la capital de la república y otras regiones del país. Para finalizar, se identificará a algunos individuos destacados de la colectividad catalana y se atenderá a su relación con el conjunto de la inmigración española, cuya parte más visible se reunía en el Casino Español.

Existen muy pocos estudios acerca de los catalanes en la ciudad de México durante el porfiriato, lo cual contrasta con su abundancia para el periodo del exilio republicano (Lida, 2009; Muriá, 1996; Pla, 2003, 1999; Tuñón, 2011) ${ }^{3}$ y con las investigaciones existentes sobre los españoles provenientes de otras regiones peninsulares (Arcelus, 2001; Domínguez y Cerutti, 2006; Garritz, 2008, 1999; Garritz y Sanchiz, 2003; González, 2009; Ruiz, 2002). No obstante, cabe destacar el estudio de Martín Pérez (2013), una aproximación a la presencia de catalanes en México durante las primeras décadas del siglo xx, con base en las fichas biográficas del Diccionario de los catalanes de

${ }^{2}$ En el porfiriato se presenció una transformación económica sin precedentes en México. La reanudación de las relaciones diplomáticas y la restructuración del crédito internacional representaban la base de la estrategia económica porfiriana. A partir de 1884, el establecimiento de acuerdos con los inversionistas de ultramar y la extensión de lazos con la economía internacional se convirtieron en los objetivos primordiales. La producción industrial se expandió con rapidez en la década de 1890 , con un carácter de dependencia respecto de la tecnología de capital intensivo como del conocimiento en gestión empresarial extranjeros; debido a la ausencia en México de maquinaria industrial, mercados de capital o mano de obra calificada. Como consecuencia de todo lo anterior, el establecimiento de la paz política fue el requisito esencial para el desarrollo económico y justificó una política autoritaria en otros ámbitos, en nombre del progreso (Garner, 2003, pp. 163-191).

${ }^{3}$ No es nuestro objetivo hacer un recuento de la bibliografía sobre el exilio catalán en México, que sin duda es muy abundante. Entre los principales referentes destacan Dolores Pla Brugat y Clara E. Lida, sobre la emigración republicana a México y algunos estudios testimoniales; José María Muriá, quien desarrolló un diccionario biográfico, o Enriqueta Tunón Pablos, con estudios también de carácter testimonial, entre otros. 
México, así como algunos expedientes de la Comisión Hispano Mexicana de Reclamaciones (1925-1932). Además, Miquel Martí (1989) realizó un estudio del Orfeó Català, a partir de las actas de las reuniones que se conservan en su archivo. El Orfeó fue, desde 1906, el espacio de reunión por excelencia de los catalanes, el cual dio cohesión institucional a la identidad catalana en México y funcionó como centro de recreo, además de cubrir necesidades mutualistas y de beneficencia. Existe también un estudio sobre la prensa catalana en México a lo largo del siglo xx que permite identificar los primeros diarios y semanarios que se publicaron en catalán en la ciudad de México (Surroca, 2000). ${ }^{4}$ Finalmente, el Diccionario de los catalanes de México, de José María Muriá (1996), recoge datos de algunos individuos que residieron en México en los años anteriores al exilio republicano. No obstante, se trata de un número muy exiguo, que no incluye a algunos destacados catalanes del periodo. Teniendo en cuenta lo anterior, el presente trabajo pretende profundizar en el conocimiento de la colonia catalana realizando un acercamiento a las festividades de esta colectividad. Lo anterior permite identificar a individuos significativos de la colectividad que no han sido reseñados en otros trabajos académicos previos, pese a que fueron figuras de referencia dentro de la colonia española y la catalana. Además, esta aproximación permite reconocer algunas motivaciones ideológicas de este grupo e identidades en conflicto con la española.

Resulta necesario señalar que la presencia catalana en México durante el periodo de estudio estuvo ligada a la de los españoles en general, debido a que los individuos que la protagonizaron ingresaron al país con un pasaporte de este origen y así fueron registrados por las autoridades migratorias de México. ${ }^{5}$ En este sentido, muchas de las características de esta colectividad fueron compartidas por el conjunto de individuos procedentes de otras regiones del país, como se verá a continuación, pero también contaron con particularidades propias, como resultado del desigual desarrollo de esta región nororiental de la península respecto de sus pares en el resto del territorio nacional, entre otras cuestiones. Así, los españoles en México eran un grupo caracterizado por México.

${ }^{4}$ Muchas de estas publicaciones no se conservan en los repositorios documentales de

${ }^{5}$ Es importante apuntar que, a lo largo del trabajo, se mantendrá la grafía de los nombres de los individuos catalanes de los cuales nos referiremos en su forma castellana, debido a que en el periodo referido no era legal que estos apelativos estuvieran escritos en otra grafía que no fuese la española. La decisión de mantener la terminología castellana pretende ser fiel a la época de estudio y no caer en anacronismos históricos. 
una escasa afluencia numérica, la cual nunca representó más de $0.2 \%$ dentro del conjunto de la población, pese a ser el grupo extranjero más numeroso. Lo anterior contrastaba con su perfil socioeconómico "privilegiado", debido a su vinculación con el mundo de los negocios y la persistencia de cadenas migratorias que hundían sus raíces en la época virreinal, enlazando con familias poderosas desde el punto de vista político, económico y social. No obstante, la presencia catalana en Nueva España había sido casi insignificante, debido a las prescripciones de la corona que impedían a catalanes y valencianos la emigración a América, aunque algunos lograron sortear estos impedimentos (Peregrina, 2013, p. 7). Lo anterior contribuye a explicar la escasa presencia catalana en la ciudad de México durante el periodo de estudio. ${ }^{6}$

En 1887 un censo levantado por la propia colonia española arrojaba un número de 9553 españoles en toda la república mexicana, mientras que el primer censo general de población de 1895 arrojó un total de 13727 y en 1910 se calcula que eran casi $30000 .{ }^{7}$ Las ciudades con mayor asentamiento de españoles fueron la ciudad de México (67\%), Puebla (3.5\%) y Veracruz (3\%). Algunos estudios han establecido que en 1882 el número de españoles en la ciudad de México era de 1595 , mientras que en 1895 la cantidad se eleva a 4124 (Jarquín, 1981, pp. 184-188; Pérez, 1999, p. 271). El 5\% de esta población provenía de la provincia de Barcelona, que era la cuarta región que arrojaba emigrantes con destino a México, por detrás de las actuales Asturias (22\%), Cantabria (18\%) y País Vasco (7\%) (Lida, 1994, pp. 25-51). Así, fueron aproximadamente entre 80 y 300 catalanes en la capital de la república para el periodo de estudio. Igual que el conjunto de españoles, se trataba de una inmigración singularizada por su inserción en sectores económicos que proporcionaban grandes capitales y beneficios, como la industria, el comercio, la banca o las empresas agrícolas, de las que en muchas ocasiones eran propietarios. Sin embargo, el grueso de la población se dedicaba al comercio, en calidad de dependientes,

${ }^{6}$ César Yáñez Gallardo (1996) realizó una investigación sobre la temprana emigración catalana a América. Aunque el estudio corresponde a una temporalidad anterior a la que se considera en esta investigación, los datos arrojan cifras muy parecidas. Así, el autor establece un estudio comparativo entre los pasaportes concedidos en Cataluña, desagregando los destinos nacionales. Entre 1845-1861, los catalanes con destino a México oscilan entre 0.7-5.1\% del total de la emigración salida del puerto de Barcelona. Muy inferior a las Antillas españolas, que absorbían entre el 60-74\% de esta emigración (p. 125).

7 Lo anterior representa un aumento promedio de unos 1500 individuos al año, aunque en realidad entre 1895 y 1910 se duplicó la entrada de españoles en México (Salazar, 2010, p. 120; Lida, 1994, pp. 30-43). 
sector en el que era común experimentar un ascenso socioeconómico tras años de trabajo (Pérez, 1981, pp. 101-173). No obstante, a los dos grupos indicados anteriormente -esto es, grandes comerciantes y dependientes de comerciose sumaban, en menor número, aquellos individuos dedicados a otras actividades laborales, así como los que se ubicaban en un escalafón social más bajo, quienes se encontraban desempleados, contaban con una escasez de recursos o estaban en situación de indigencia (Gil, 2015).

Antes de continuar, resulta importante realizar una breve contextualización del marco general de la diplomacia bilateral entre México y España durante este periodo. A este respecto, las relaciones entre ambos países se habían suspendido en 1867, como consecuencia del reconocimiento por España del gobierno imperial de Maximiliano de Habsburgo -derrotado finalmente en 1867 por la facción liberal, liderada por Benito Juárez. Las gestiones para reactivar las relaciones entre México y España no se materializarían sino hasta la década de 1870, cuando llegó a México el ministro de España Feliciano Herreros de Tejada (1871). No obstante, la normalización de las relaciones se produciría tras el ascenso de Porfirio Díaz a la presidencia de la república, quien inició un largo periodo de gobierno conocido como porfiriato (1876-1911), el cual coincidió con la Restauración Borbónica en España (1875-1931). ${ }^{8}$ Estos procesos se caracterizaron por la instauración de una época de paz y estabilidad política en ambos países, que dieron lugar a una progresiva consolidación de las relaciones internacionales entre México y España. Conforme la diplomacia bilateral se fue afianzando, los españoles estuvieron cada vez más interesados en desarrollar sus negocios al amparo de concesiones gubernamentales -en un contexto de crecimiento económico de México y de consolidación del régimen de Díaz- y también lo estuvo la Legación Española en el país, deseosa de impulsar el comercio entre México y España. Con este objetivo se creó la Cámara Española de Comercio (1889), como se explicará con mayor detenimiento más adelante. ${ }^{9}$

${ }^{8}$ La Restauración Borbónica supuso la reinstauración en el trono español de la monarquía Borbón -concretamente Alfonso XII- tras la experiencia de la I República (1873-1874). Fue una época caracterizada por la paz y la estabilidad política, la cual alternó en el gobierno a conservadores y liberales (instaurando el llamado "turno pacífico").

${ }^{9}$ Son numerosos los investigadores que se han dedicado al estudio de las relaciones internacionales entre México y España. En relación con la cronología y la temática abordada en el presente artículo, destacamos los trabajos de Agustín Sánchez Andrés, Antonia Pi-Suñer, Pedro Pérez Herrero, Josefina MacGregor y Alicia Gil Lázaro (Gil, 2015; MacGregor, 1992; Pi-Suñer y Sánchez, 2001; Sánchez, 1999; Sánchez y Pérez, 2015). 


\section{LA CELEBRACIÓN DE LA FESTIVIDAD DE MONTSERRAT (1887-1892)}

\section{Los catalanes y el Casino Español: negocios y política}

En este apartado, los periódicos de la colonia española, así como algunos órganos de prensa mexicanos, constituyen la fuente principal en que nos hemos apoyado para la elaboración de la investigación. ${ }^{10}$ Para el periodo en estudio, las publicaciones españolas -El Pabellón Español (1883-1890), La Nueva Iberia (1887-1888) y El Correo Español (1889-1914)- se encontraban en manos de individuos relacionados con el Casino Español, por lo que estos periódicos pueden considerarse voceros de esta asociación. El Casino Español era el lugar en el que se reunían los españoles mejor posicionados desde el punto de vista social y económico, lo que otorgaba reconocimiento y capital social a sus miembros y les permitía abanderar la defensa de los intereses españoles en México, así como presentarse como intermediarios y figuras de referencia respecto al resto de españoles en el país. ${ }^{11}$ Además, estos sectores acomodados administraban también otra importante institución de carácter asistencial y étnica, la Sociedad de Beneficencia Española, tratando así de dar respuesta a las diferentes necesidades del colectivo español. De hecho, la agrupación de mayor fortaleza durante el periodo -que aglutinaba el mayor número de socios- fue la Beneficencia Española. Como indica Alicia Gil Lázaro, la renovación de los cuadros directivos de la Beneficencia Española, el Casino Español y, más tarde, de la Cámara Española de Comercio, revela una rotación de cargos entre ellas, de tal modo que una pequeña elite mantuvo el poder durante varias décadas (Gil, 2015, pp. 126-134).

${ }^{10}$ Para el periodo propuesto en este apartado, las fuentes documentales diplomáticas -resguardadas en el Archivo Histórico de la Embajada de España en México- no arrojan información específica acerca del colectivo catalán ni de las celebraciones de Montserrat.

${ }^{11}$ La importancia del Casino Español radica en que aglutinaba a los individuos mejor posicionados de la colectividad española, cuyas fortunas habían florecido gracias al éxito de los negocios que habían impulsado en México. Así, ricos propietarios, industriales, banqueros o empresarios se reunían en el Casino, lugar en el que fortalecían sus lazos económicos mediante el contacto con otros grandes hombres de negocios y donde llevaban a cabo una sociabilidad restringida con otros miembros de su mismo nivel socioeconómico, lo que aumentaba su reconocimiento como miembros de la elite. En este sentido, eran la "flor y nata" de la colectividad española, relacionados con la elite mexicana y diferenciados del resto de españoles que vivían en México (Gutiérrez, 2004; Herrera, 1998). 
A finales de la década de 1880 , un grupo de catalanes residente en la ciudad de México decidió comenzar la celebración de una festividad propia, la conmemoración de la Virgen de Montserrat. En origen, esta celebración religiosa se relaciona con el proceso de Reconquista en España, aunque la principal advocación mariana ligada con este momento histórico es la Virgen de Covadonga.$^{12}$ La Reconquista hacía referencia al carácter cristiano de la guerra, su deseo de expulsar a los invasores árabes y al protagonismo de Castilla a la hora de promover la unidad de la futura España. Sin embargo, la centralidad de Castilla invisibilizaba la participación y las aportaciones de Navarra, Aragón y Cataluña en la Reconquista, que eran menospreciadas por la historiografía nacional oficial (Ríos, 2005, p. 391). Por ello, desde comienzos del siglo XIx, la historiografía catalana trató de recuperar los aportes realizados desde este territorio, para integrar plenamente en el discurso nacional la participación de Cataluña en la Reconquista..$^{13}$ El equivalente de don Pelayo en la región oriental era el conde Wifredo el Velloso y Montserrat se asemejaba a la Covadonga. ${ }^{14}$

${ }^{12}$ La Reconquista se refiere al periodo comprendido entre la invasión árabe de la península ibérica, con la consiguiente conformación del territorio de Al-Andalus, y la conquista de Granada por los grupos cristianos en 1492, que terminó con el dominio político de los árabes en la península. La Reconquista comenzó en 1722, con la Batalla de Covadonga (Asturias), cuando una tropa cristiana al mando de don Pelayo derrotó al ejército de Al-Andalus. Según la tradición, la intervención de la Virgen de Covadonga habría determinado la victoria de don Pelayo y su ejército. La centralidad de la Reconquista y la Covadonga en la construcción de la identidad nacional española a finales del siglo XIX alcanzó tal grado de importancia que entre los españoles en México dio lugar al origen de la celebración homónima -las fiestas de la Covadonga-, festejada anualmente desde la década de 1880 (Gutiérrez, 2016, pp. 37-52).

${ }^{13}$ Los historiadores de esta década se sumaron al discurso nacional oficial para integrarse plenamente en el proyecto nacional y asumieron como propia la concepción histórica que manifestaba que España se había forjado luchando contra los árabes a lo largo de ochos siglos (Ríos, 2011, pp. 190-191). Cabe señalar que el surgimiento de la historiografía catalana se ubica en el contexto de eclosión del catalanismo cultural -también conocido como Renaixença-, surgido en las primeras décadas del siglo XIX, pero que alcanzó su esplendor en la segunda mitad del siglo. Aunque el interés de este movimiento fue, sobre todo, en el ámbito literario, tuvieron gran importancia los poemas y narraciones de exaltación historicista.

${ }^{14}$ Con la llegada de los árabes a la península ibérica (711), el territorio de Cataluña pasó a formar parte de Al-Andalus, hasta que en la segunda mitad del siglo viII las intervenciones francas al sur de los Pirineos crearon la Marca Hispánica, formada por condados gobernados por un personaje de nombramiento real. Así, este territorio, que coincidía aproximadamente con los límites de la actual Cataluña, quedaba integrado en el Imperio Carolingio. A fines del siglo IX, en una época de regionalización del poder, Wifredo el Velloso ostentaba los condados de Cerdaña, Urgel, Barcelona y Gerona. Durante su gobierno fortaleció su linaje frente a la aristocracia franca, convirtió su poder en hereditario y patrimonial e impulsó la colonización 
Las primeras referencias a la festividad de Montserrat en la ciudad de México corresponden al año 1887, cuando el 8 de septiembre se celebró una misa en la iglesia de Nuestra Señora de Montserrat. ${ }^{15}$ Después del oficio religioso, un grupo de catalanes se reunió para almorzar en la casa del industrial Laureano Salazar, propietario -junto con Teodoro Salvans- de la fábrica de jabón y productos de perfumería La Catalana ${ }^{16} \mathrm{La}$ Voz de México reseñó que la función religiosa estuvo "brillantísima" y que "la colonia catalana asistió, sin excepción de clases, a la fiesta de su Patrona, así como muchísimos españoles residentes en esta capital. La iglesia se hallaba de tal manera llena de gente, que se hacía casi imposible la entrada. ${ }^{17}$ Estos datos permiten determinar que la festividad de Montserrat fue organizada por acaudalados catalanes, aunque estaba destinada al conjunto de españoles y contaba con una asistencia interclasista -en lo que respecta al oficio religioso, probablemente no fue así en el banquete-. Además, es importante señalar que tuvieron una presencia destacada en la celebración los individuos del Casino Español, que en 1888 enviaron dos representantes: José Román Leal y Joaquín Victorero. ${ }^{18}$ Ese año, la logística de la fiesta fue responsabilidad de una comisión formada por los comerciantes Baldomero Giralt y José Contel, pertenecientes ambos también al Casino Español. ${ }^{19}$

de las tierras centrales de la futura Cataluña. Debido a estas características, la historiografía ha adjudicado la conformación de una incipiente independencia de Cataluña a Wifredo el Velloso, quien es concebido como héroe nacional (Canal, 2015, pp. 23-28; Capdeferro, 1990, pp. 34-35).

${ }^{15}$ El templo de la Virgen de Montserrat se refiere a la iglesia de San Jerónimo, donde se había trasladado la figurilla de la Virgen tras las Leyes de Reforma.

${ }^{16}$ La casa de Laureano Salazar se encontraba en la calle de Necatitlán 1. En esta calle se encontraba también la fábrica La Catalana. "La Catalana", El Correo Español, 24 de febrero de 1891; "Invitación", El Tiempo, 7 de septiembre de 1887; "La colla de Montserrat", El Nacional, 8 de septiembre de 1887; "La colla de Montserrat", La Defensa Católica, 8 de septiembre de 1887.

17 "Función religiosa a Nuestra Señora de Montserrat", La Voz de México, 11 de septiembre de 1887.

${ }^{18}$ Joaquín Victorero formaba parte de la estudiantina del Casino Español. También fue vocal de la Sociedad de Beneficencia Española en diversas ocasiones. Respecto a su ocupación, en 1874 aparece como dueño de un almacén de abarrotes, junto con José Mijares. "Nueva casa de comercio", La Iberia, 23 de marzo de 1874.

${ }_{19}$ Baldomero Giralt fue también vocal de la Sociedad de Beneficencia Española. Por su parte, José Contel se desempeñaba asimismo como director de zarzuela y formaba parte de la Sociedad Filarmónica "Ángela Peralta". Véase: Commercial directory of the American Republics, vol. II (1898), p. 114; "La semana en el pentagrama”, El Cronista Musical, 19 junio 1887; "Elecciones”, El Cronista Musical, 23 de octubre de 1887; "Veracruz", La Patria, 7 de junio de 1910. 
Sobre los datos anteriores, resulta necesario señalar que, desde 1887, el Casino Español comenzó un proceso de acercamiento a la elite política porfiriana, el cual se intensificó conforme avanzaron los años, lo que dio lugar a que algunos individuos se refirieran a esta asociación, de manera irónica, como "Casino Tuxtepeco". ${ }^{20}$ Esta aproximación comenzó desde la entrada en la presidencia del Casino Español de Juan Llamedo, quien sería reelegido por los siguientes tres años, y que representaba a una nueva generación de españoles -individuos jóvenes, pertenecientes a una incipiente elite económicadeseosa de adquirir influencia en los círculos de poder para obtener concesiones gubernamentales en las que pudieran invertir sus capitales y aumentar sus negocios. ${ }^{21}$ Los datos existentes acerca de Joaquín Victorero y Baldomero Giralt apuntan a que estos individuos -quizá también José Contel- formaban parte de esta joven generación de españoles. Por su parte, José Román Leal fue el fundador y director de La Nueva Iberia (1887-1888), un órgano de prensa que se creó para aquellos industriales y comerciantes españoles que deseaban el desarrollo económico de México para impulsar sus negocios con facilidades y garantías. La Nueva Iberia fue favorable al gobierno de Porfirio Díaz y estuvo al servicio de la nueva generación de españoles que acababa de ganar la directiva del Casino (Gutiérrez, 2019, p. 321). En suma, el esfuerzo por introducir la Montserrat en México y el fomento de la reunión de catalanes en la ciudad se llevó a cabo por miembros de esta región pertenecientes al Casino, en pleno proceso de acercamiento a la elite política.

En 1889 se celebró de nuevo la ya tradicional misa en la iglesia de Montserrat, con "trofeos de banderas mexicanas y españolas [...] como en un abrazo [...] de íntima alianza y confraternidad", a la que asistió la representación oficial española en el país, diversos periodistas españoles y muchas personas de la alta sociedad mexicana y catalana. El banquete posterior fue presidido por el Barón de la Barre de Flandes (Encargado de Negocios de la Legación de España en México), Francisco de Paula Flaquer y José Barbier, periodistas de origen español, directores de La Crónica y La Voz de España en América, respectivamente. El convite, al que acudieron cerca de 40 personas,

\footnotetext{
${ }^{20}$ En referencia a la revolución de Tuxtepec (1876), que había llevado a Porfirio Díaz a la presidencia.

${ }^{21}$ Desde 1876 Juan Llamedo era proveedor de trajes del ejército y había apoyado abiertamente la rebelión de Tuxtepec, la cual llevó a Díaz al poder. Su cercanía con el primer magistrado y con otros miembros prominentes de la colonia española permitió su participación en la apertura del Banco de Londres y México (Gutiérrez, 2004, pp. 109-110).
} 
contó con un menú "puramente español” y estuvo signado por las referencias a la importancia de la industria catalana. ${ }^{22}$ Los datos anteriores muestran que la celebración de los catalanes no era desinteresada. Cataluña era mostrada ante la sociedad mexicana como la región más desarrollada de España y como sinónimo del progreso económico deseado por el régimen de Díaz. Al respecto, cabe señalar que en 1888 se había celebrado la Exposición Universal de Barcelona, que fue la primera de su tipo en España y había situado al país en el concierto de las naciones modernas. ${ }^{23}$ En suma, la importancia de Cataluña en la España de finales del siglo xix se relacionaba con su relevancia en el área comercial e industrial, que durante gran parte del siglo xix fue la excepción en una España caracterizada por una economía agraria y agroexportadora. Así, Barcelona se encontraba en el primer puesto de los sectores industriales modernos del país, muy lejos de las demás provincias (Balcells, 1977, p. 83). Sobre este aspecto, el encargado de Negocios había pronunciado un brindis en 1888 en el cual elogiaba a "los catalanes, que tan alta han puesto la honra de España en la exposición de Barcelona, donde ha concurrido [...] todas las grandes naciones a saludar el triunfo industrial de la ciudad". ${ }^{24}$ Lo anterior nos muestra que el interés por acercarse al régimen de Porfirio Díaz -en un contexto de crecimiento económico del país y de apertura al ámbito internacional- no era privativo de las elites económicas españolas y catalanas en México, sino que también participaba de ello la Legación de España en el país. Así, la representación oficial, que en los años anteriores había fortalecido los lazos diplomáticos con el gobierno de Díaz, se incorporó desde 1888 a las celebraciones del colectivo catalán.

En relación con lo anterior, cabe mencionar que Segismundo Moret -ministro de Estado del gobierno liberal de Práxedes Mateo Sagasta (18851888) - había concebido la firma de un tratado comercial entre México y

22 "Colla de Montserrat", El Tiempo, 15 de septiembre de 1889; "Una fiesta catalana", El Pabellón Español, 10 de septiembre de 1889.

${ }^{23}$ Mauricio Tenorio (1998, pp. 14-18) señala que las exposiciones universales decimonónicas fueron la quinta esencia de la modernidad y las ciudades que actuaban como sede de estos actos eran importantes núcleos financieros, culturales e industriales, referentes universales del progreso para el mundo occidental. El autor señala la importancia de reconocer el artilugio que se ponía en marcha en estas exposiciones, las cuales servían para satisfacer una autoimagen que se deseaba proyectar al resto del mundo. Por otro lado, las exposiciones servían también para celebrar acuerdos y comisiones comerciales para promover el intercambio de materias primas y bienes manufacturados entre países.

24 “Los catalanes en México", La Nueva Iberia, 11 de septiembre de 1888. 
España como parte de una activa política exterior implementada hacia América Latina, de la que México era el eje central. La insignificancia del volumen de intercambios entre México y España contrastaba con la enorme actividad económica de los miembros del Casino Español (Pi-Suñer y Sánchez, 2001, pp. 276-277). En consecuencia, desde fines de 1886, la creación de la Cámara de Comercio Española en México era un objetivo prioritario de la Legación Española en el país. Como indica Aurora Cano (2009), el objetivo de establecer Cámaras de Comercio en el exterior era crear corrientes comerciales entre España y el resto del mundo, así como promover la organización de los empresarios españoles en torno a una asociación que los representara y contactara con España. Así, se exhortaba a la creación de estas instituciones bajo una retórica patriótica en la cual el comercio con el exterior impulsaría el desarrollo de España, mientras que sus artífices serían los propios españoles dedicados al comercio que residieran en el extranjero, bajo la supervisión de diplomáticos o cónsules (pp. 83-85). Al respecto, resulta evidente el interés de los empresarios e industriales catalanes en la ciudad de México por impulsar acuerdos favorables con el gobierno de Porfirio Díaz, en la coyuntura de la Circular de Moret y aprovechando la apertura económica que experimentaba en esas fechas el régimen. Así, la festividad de Montserrat, a la que se invitaba a ricos empresarios y políticos españoles y mexicanos, fue utilizada para recrear la importancia de Cataluña en el ramo comercial e industrial, además de favorecer la sociabilidad entre individuos ubicados en la elite de la sociedad. En la creación de la Cámara Española de Comercio -que finalmente se fundó en diciembre de 1889- tuvieron una participación destacada los miembros del Casino Español quienes, como ya se ha visto, eran también los principales cuadros directivos de la Sociedad de Beneficencia Española.

\section{Auge y caída de la fiesta de Montserrat. Fricciones en torno a la celebración catalana}

La última década del siglo xIx parecía augurar un futuro prometedor para la celebración septembrina de Montserrat, la cual, en 1890 experimentó una mejoría notable en lo que respecta a su planeación y organización, realizada con mucha mayor anticipación y profusión que los años precedentes. Así, los catalanes se reunieron con un mes de antelación en la casa de Laureano Salazar, bajo la presidencia del encargado de Negocios, con el objetivo de formar 
una junta permanente que fuese la encargada de la organización de los festejos. La junta estaba compuesta por el conocido músico y poeta Narciso Bassols ${ }^{25}$ Laureano Salazar; Ramón Borrell, empresario y comerciante que proveía de avituallamiento a los cuerpos de caballería e infantería; ${ }^{26}$ José Daniel Bousquet, apoderado y gerente de la compañía Trasatlántica Española; ${ }^{27}$ Enrique Farell, dueño de una importante relojería -situada en la calle de Independencia-, ${ }^{28}$ y Juan Salazar (hijo de Laureano Salazar). Entre otras cuestiones, en la reunión se acordó poner en comunicación a la colla de Montserrat ${ }^{29}$-término habitual con el que los catalanes se referían a esta festividad-con los centros catalanes de Madrid, Cuba y otros puntos extranjeros, lo que demuestra el auge de la identidad catalana en la península y en el extranjero. ${ }^{30}$

El 17 de agosto de 1890 los catalanes organizaron una fiesta de despedida al encargado de Negocios, el señor Barón de la Barre de Flandes -quien se marchaba de México para ocupar el puesto de ministro plenipotenciario de España en Constantinopla-, en el Tívoli del Elíseo. La relación de asistentes a esta celebración nos ha permitido identificar los nombres de varios catalanes destacados que no habían sido mencionados con anterioridad, así como el perfil social de algunos de ellos. A la celebración asistieron Cayetano Quintara; Laureano Salazar; Juan Salazar; Juan Griñó; Ángel Coronas; Teodoro

${ }^{25}$ Llegó a Veracruz en 1852, desde donde se trasladó a Puebla. En esta ciudad fue redactor en la Revista Eclesiástica y participó activamente en las actividades de la Sociedad de Beneficencia Española, así como en la conformación del "Círculo Poblano". Fue padrino de la fábrica de papel La Constancia Catalana, propiedad de los señores Bassols y Costa, ubicada en Tacubaya. "Correo de Veracruz", El Siglo XIX, 16 de abril de 1852; "La Junta Española de Beneficencia", El Amigo de la Verdad, 31 de marzo de 1883; "Sermonario mexicano", El Amigo de la Verdad, 27 de abril de 1889; "El Sermonario mexicano", El Amigo de la Verdad, 24 de mayo de 1890; "Fiesta", El Correo Español, 1 de octubre de 1890; "Círculo poblano", Periódico Oficial del Estado de Puebla, 4 de junio de 1891.

26 "Contrata", La Iberia, 13 de junio de 1874; Periódico Oficial del Estado de Puebla, 22 de marzo de 1891, p. 6; "Colla de Montserrat", El Tiempo, 15 de septiembre de 1889.

${ }^{27}$ Además, participó en otras iniciativas comerciales, teniendo una participación directa en diversas empresas mercantiles y navieras. "D. José Daniel Bousquet", El Correo Español, 31 de agosto de 1909.

${ }^{28}$ Véase, por ejemplo, la sección de anuncios de El Tiempo del día 22 de octubre de 1893. Asimismo, Enrique Farell fue tenor de ópera y zarzuela, perteneciente a la Sociedad Filarmónica "Ángela Peralta". Participó en diversas funciones artísticas en la capital mexicana desde la década de 1880. "Programa", La Patria, 21 de octubre de 1885; "Sociedad Filarmónica Ángela Peralta", Le Trait d'Union, 2 de marzo de 1888; "Programa", El Siglo XIX, 7 de marzo de 1889.

29 "Colla" (catalán) se traduce en español como "formación" o "equipo".

30 "La reunión de la colonia catalana", El Correo Español, 12 de agosto de 1890. 
Salvans; Federico Viñas; Ramón Alentá, dueño de un establo ganadero y una fábrica de almidón; ;1 Ángel Bassols, socio propietario de una Casa Comisionista $^{32}$ e hijo de Narciso Bassols; Agustín Soler, copropietario junto con Leopoldo Barroso de la sastrería Soler y Compañía, dirigida a la alta sociedad mexicana; ${ }^{33}$ Francisco Carles, ligado al mundo editorial y traductor de numerosas obras; ${ }^{34}$ Ramón Oller; Fernando Rafols, industrial propietario de una fábrica de licores ${ }^{35}$; Ignacio Montaner; Valero Montserrat; Enrique Farell y Antonio Sivillá; todo lo cual confirma el interés por impulsar la Montserrat en México por una parte importante de ricos hombres de negocios e industriales catalanes. ${ }^{36}$

31 “A la exposición de ganadería”, El Tiempo, 31 de octubre de 1893; Guía General Descriptiva de la República Mexicana, 1899, pp. 337-338.

${ }^{32}$ Este tipo de casas refieren a las empresas que en los diversos mercados centrales gestionaban y llevaban a cabo transacciones bursátiles. "Sucesos de policía", El Correo Español, 3 de abril de 1892; "Varias noticias", 4 de abril de 1892; "Matrimonios", El Amigo de la Verdad, 12 de marzo de 1892.

${ }^{33}$ Fundada en 1878, "Soler y Compañía" se encontraba situada en los bajos del Hotel Nacional. La sastrería se dirigía a una clientela exclusiva, pues se caracterizaba por la calidad de sus telas, provenientes de Francia e Inglaterra. A fines de 1879, Agustín Soler mantuvo un enfrentamiento con el sastre parisino Celestino Hourcade, también residente en la capital mexicana, con quien se disputaba la clientela de la alta sociedad. Asimismo, Soler fue sastre y cortador de los alumnos del Colegio Militar y en 1880 confeccionó el traje que utilizó Manuel González para la toma de posesión de la presidencia de la república. "Sastrería", La Libertad, 30 de octubre de 1878; "Varias noticias", La Libertad, 7 de diciembre de 1879; "D. Agustín Soler", La Libertad, 7 de diciembre de 1879; "El frac del general González", La Patria, 12 de noviembre de 1880; "Toda la prensa", La Patria, 14 de noviembre de 1880; "Los alumnos del Colegio Militar", La Patria, 23 de octubre de 1881.

${ }^{34}$ Entre las traducciones de Francisco Carles destacan las de los autores franceses Pierre Alexis Ponson du Terrail o Alphonse Daudet. También tradujo al español la obra El castellano convertido; novela de costumbres húngaras, del autor de este origen Mór Jókai; diversas narraciones de Tolstoi, como El Matrimonio o Sonata a Kreutzer; así como de los ingleses Mary Elizabeth Braddon, Hugh Conway, Wilkie Collins, Eustace Clare Grenville Murray o el autor belga Léopold Stapleaux, entre los más destacados. La Biblioteca Nacional de España (BNE) conserva 43 ejemplares cuya traducción fue realizada por Francisco Carles desde 1883 y hasta la primera década del siglo $\mathrm{xx}$.

35 "Importante al comercio", El Tiempo, 21 de noviembre de 1885; "Se trasladó", El Nacional, 6 de agosto de 1887; Boletín Semestral de la Estadística de la República Mexicana, junio de 1891, p. 194.

${ }^{36}$ Como afirma Javier Moreno, la procedencia geográfica de los comerciantes influyó en la naturaleza de sus empresas. Los inmigrantes españoles adoptaron en México los modelos empresariales que les eran más familiares, como demuestra la dedicación preferente de vascos y catalanes a las actividades industriales. Así, $2.7 \%$ de la industria fabril de la ciudad de México estaba en manos de catalanes en 1914, muy por encima del resto de provincias españolas, mientras que los catalanes representaban tan sólo el 3.5\% de los empresarios de este origen, muy 
Al término del festejo anterior, una asamblea acordaba

constituir un Centro Español bajo la denominación de La Colla de Montserrat, a la cual puedan pertenecer como socios, todos los españoles originarios del antiguo Reino de Aragón, y a cuya sociedad no se le da ningún carácter opuesto a las actuales corporaciones españolas existente en la Capital de la República, pues no tiene más objeto que el interés privado de sus asociados en materia de socorros mutuos, recreo y fraternidad. ${ }^{37}$

La comisión organizadora para la formación de dicho centro estaba compuesta por Narciso Bassols (presidente); José Daniel Bousquet (vicepresidente); Laureano Salazar (tesorero); Emilio Cuenca; ${ }^{38}$ Baldomero Giralt; Ramón Borrell; Enrique Farell; Pablo Rubira, propietario de la empresa textil Pablo Rubira y Cía., destinada a la edificación y explotación de una fábrica moderna de hilados y tejidos, Cía. Industrial La Virgen S. A.;9 Gabriel Orduña, corredor de comercio $;^{40}$ José María Foradada (vocales) y Juan Salazar (secretario). Se nombró presidente honorario al ministro de España, así como a los presidentes de las juntas directivas del Casino Español y la Sociedad de Beneficencia Española. Si la Colla de Montserrat hubiese llegado a conformarse institucionalmente habría sido la primera asociación regional de la colectividad española en el país, por lo que puede afirmarse que constituye un importante antecedente que merece ser considerado en estudios posteriores. Sin embargo, no existe evidencia documental de que este centro llegara a fun-

por debajo de asturianos (41\%) y cántabros (21\%), quienes no obstante se dedicaban en mayor medida a negocios crediticios y agropecuarios (Moreno, 2007, pp. 122-124).

37 "La despedida del Sr. Barón de la Barre", El Correo Español, 19 de agosto de 1890.

${ }_{38}$ Desde 1890 estuvo facultado por Ricardo Sainz, importante industrial del ramo papelero, para hacerse cargo de la correspondencia y facturas de la Litografía Española y dos años más tarde ya aparece al frente de una compañía propia: la Litografía Comercial o Emilio Cuenca y Cía. Era de origen aragonés. "Pasajeros", El Siglo XIX, 26 de noviembre de 1885; "Circular mercantil”, El Correo Español, 6 de marzo de 1890; "Almanaque”, La Patria, 11 de enero de 1895.

${ }^{39}$ La sociedad Pablo Rubira y Cía. se constituiría en 1894, aunque Pablo Rubira murió a fines de ese año. Desconocemos las actividades a las que se dedicó en los años anteriores. "Sensible defunción", Semana Mercantil, 26 de noviembre de 1894; "Agricultura, Industria y Comercio", Semana Mercantil, 8 de julio de 1895; Herrero (2004, p. 128).

${ }^{40}$ También fue delegado de la Cámara de Comercio de Tlacotalpam (Veracruz) ante la Confederación Mercantil de la República en el año 1887. "Confederación Mercantil de la República”, El Tiempo, 21 de diciembre de 1886; "Consulado de España en México”, El Correo Español, 26 de junio de 1900. 
darse, pues ninguna referencia posterior lo consigna como tal. Es posible que lo anterior se debiese a la acción ejercida en contra por un sector del Casino Español. Se trataba, en realidad, de un proyecto largamente acariciado por Laureano Salazar, quien desde 1888 había propuesto "la instalación de una sociedad catalana para reunirse semanalmente". La proposición había chocado con el rechazo del encargado de Negocios y otros miembros del Casino Español, quienes habían argumentado que se podía crear en este último una sección catalana, pero no de manera separada, pues el Casino constituía "la casa establecida única y común en esta capital de todos los españoles, sin distinción de procedencias regionales [...] a los catalanes se debe principalmente amor y gratitud, por los grandísimos títulos que tienen adquiridos en las glorias de España en Oriente, y a última en la campaña industrial de los tiempos modernos". ${ }^{41}$

La festividad anual de Montserrat fue un evento organizado por los acaudalados miembros de la colectividad catalana, aunque la celebración estaba abierta al conjunto de españoles y la sociedad mexicana. Esto último buscaba la creación de un espacio de sociabilidad entre pares que eventualmente pudiese favorecer el establecimiento de acuerdos y tratados comerciales, así como la fundación de una Cámara Española de Comercio en el país, como finalmente sucedió en 1889. El fomento a la industria y el comercio internacionales, favorecidos por el régimen de Porfirio Díaz -lo que se incrementaría en los años siguientes-, así como el interés de España en establecer acuerdos favorables con México en este sentido, condujo a la exaltación de Cataluña y los comerciantes e industriales de este origen como el súmmum de una España progresista y capitalista. El progresivo acercamiento entre estos sectores privilegiados de la sociedad española y mexicana se materializó aquel año de 1890 con la celebración de la fiesta en el Tívoli del Eliseo -que sustituía al ya tradicional banquete en la casa de Laureano Salazar-, lugar de esparcimiento de la alta sociedad mexicana, donde tuvo lugar "un banquete fraternal de 100 cubiertos", un concierto y un baile. ${ }^{42}$ Los asistentes formaban parte de "lo más granado" de la sociedad mexicana y española y entre ellos se

41 “Los catalanes en México”, La Nueva Iberia, 11 de septiembre de 1888.

42 "Las fiestas de Montserrat", El Nacional, 10 de septiembre de 1890; "La fiesta de la colla de Montserrat”, El Correo Español, 11 de septiembre de 1890. 
encontraban Lorenzo de Castellanos (ministro de España) y Ricardo Lasqueti (cónsul de España) ${ }^{43}$ (véase cuadro 1).

No obstante el ascenso fulgurante que había experimentado la celebración de Montserrat los años anteriores, en 1892 El Correo Español publicaba una nota que tendría profundas implicaciones para los catalanes y la Montserrat en años posteriores, exponiendo

la necesidad y conveniencia de que para mayor gloria de España y unión de todos los compatriotas, se procure con noble ahínco celebrar cada año una fiesta puramente española y en día que represente fecha inmemorable. Para ello, y en nuestro sentir, tenemos los españoles dos festividades: la de Santiago, en el mes de Julio, y la de la Concepción, el 8 de diciembre, patronos ambos de España y, por consiguiente, muy adecuados para que los hijos de todas las provincias puedan dar gallardas muestras de su amor y adhesión a la madre patria. Creemos, pues, que una de esas dos fechas, u otra análoga, debiera ser elegida para la celebración de una verdadera e importante fiesta española. ${ }^{44}$

El artículo anterior sugería la necesidad de cambiar la celebración catalana por otra "puramente española". Sin embargo, la festividad que se eligió no fue la de Santiago en julio o la de Concepción en diciembre, como preveía la nota anterior, sino que se optó por dar mayor centralidad a la Covadonga, que desde hacía años se celebraba en la hacienda de Coapa -perteneciente al rico asturiano José Toriello Guerra. Igual que Montserrat, la Covadonga se festejaba el 8 de septiembre, era una celebración exitosa y contaba con una junta encargada de su administración, todo lo cual opacaría la celebración catalana ${ }^{45}$ La romería de Coapa mostraba también otras similitudes con la fiesta de Montserrat, pues se caracterizaba por una celebración religiosa en la capilla de la hacienda y un banquete y baile posteriores (Gutiérrez, 2016). A partir de 1893 la Covadonga comenzó a celebrarse en el Tívoli del Eliseo, el cual desde 1890 había sido ocupado por la colectividad de origen catalán. Lo

43 "La fiesta de Montserrat", El Correo Español, 8 de septiembre de 1890; "Las fiestas de Montserrat", El Correo Español, 10 de septiembre de 1890; "La fiesta de la colla de Montserrat", El Correo Español, 11 de septiembre de 1890; "Reportajes de la romería de Coapa...", El Correo Español, 12 de septiembre de 1890.

44 "La fiesta de los catalanes", El Correo Español, 10 de septiembre de 1892.

${ }^{45}$ El 8 de septiembre era la fecha de celebración de muchas advocaciones marianas, por ser fecha de la Natividad de Nuestra Señora. 


\section{Cuadro 1. Catalanes destacados de la ciudad de México entre 1887-1892a}

Nombre

Actividad

Negocio

Laureano Salazar Propietario de industria

La Catalana, fábrica de jabón y productos de perfumería

Teodoro Salvans Propietario de industria

La Catalana, fábrica de jabón y productos de perfumería

Baldomero Giralt Comerciante

José Contel Comerciante

Narciso Bassols Músico y poeta

Ramón Borrell Empresario y comerciante

Contratista del gobierno.

Proveía de avituallamiento al ejército mexicano

\begin{tabular}{|c|c|}
\hline $\begin{array}{r}\text { José Daniel } \\
\text { Bousquet }\end{array}$ & Industria naviera \\
\hline Enrique Farell & Dueño de negocio \\
\hline Ramón Alentá & Propietario de industria \\
\hline Ángel Bassols & Dueño de negocio \\
\hline Agustín Soler & Dueño de negocio \\
\hline Francisco Carles & Traductor, mundo editorial \\
\hline Fernando Rafols & Propietario de industria \\
\hline Pablo Rubira & Propietario de industria \\
\hline
\end{tabular}

Gerente de la Cía. Trasatlántica Española

Relojería en la calle Independencia

Fábrica de almidón y establo ganadero

Casa Comisionista

Soler y Cía., sastrería

Fábrica de licores

San Antonio Abad (Zinapécuaro, Michoacán), fábrica de hilados y tejidos

Juan Buxó

Dueño de negocio

Librería La Madrileña

a No se vuelven a repetir todas las citas previas para no entorpecer la lectura del texto. Sólo se incluyen aquellos que ha sido posible identificar por su ramo de actividad y negocio.

Fuente: elaboración propia a partir de la información proporcionada por las notas de prensa citadas en las páginas anteriores. 
anterior respondía al llamado realizado para unificar la festividad de los españoles, lo cual desposeyó de su espacio a los catalanes. Es necesario mencionar que aún ese año de 1893 los catalanes tuvieron la intención de celebrar su festejo anual, pues en agosto enviaron una carta a El Correo Español donde se avisaba de la fiesta de Montserrat y se solicitaba la contribución pecuniaria habitual, de carácter voluntario, que se depositaría en la Librería Madrileña, del catalán Juan Buxó (Gutiérrez, 1999, p. 304; Pérez, 2013, p. 91). ${ }^{46}$ No obstante, se trata de la última referencia a la fiesta catalana, la cual dejó de celebrarse a partir de 1893. En lo sucesivo, la Covadonga se convirtió en la celebración por antonomasia de los españoles en México e incluyó en su seno el conjunto de identidades regionales. En definitiva, la fiesta catalana fue absorbida por la prestigiosa Junta de Covadonga, órgano conformado por los españoles mejor posicionados desde el punto de vista socioeconómico, lo que dio mayor visibilidad pública al elemento español en la capital del país, en detrimento del catalán. Aunque no existen más datos al respecto, es posible que la sustitución de la Covadonga por la Montserrat fuese orquestada por varios hombres de negocios españoles, quienes veían opacadas su posibilidad de proyección social y desarrollo de negocios por sus influyentes pares de origen catalán.

No obstante, cabría considerar una hipótesis paralela a la anterior, relacionada con la enorme división que caracterizaba a los españoles en estas fechas y el enfrentamiento crónico entre diversos grupos de interés, por razón de diferencias sociales, regionales o personalistas, entre otras (Sepúlveda, 2005, p. 386). Aunque no ahondaremos más en el aspecto anterior, ${ }^{47}$ resulta necesario sugerir que la fiesta de Covadonga fuese utilizada en México como elemento de cohesión entre los españoles residentes en la capital, pues se trató de una festividad de carácter interclasista, a la que acudían el conjunto de españoles, y con la que se sentían identificados un mayor número de connacionales que la festividad de Montserrat. Al margen de las vicisitudes que atravesaron los españoles en años sucesivos, la Covadonga se celebró anualmente, sin excepción, hasta el estallido de la revolución.

46 "La Colla de Monserrat", El Correo Español, 31 de agosto de 1893.

${ }^{47}$ Las tensiones, los conflictos y los desencuentros de los españoles en la ciudad de México por diversos motivos -cuestiones de clase, regionales, personalistas, políticas, etc.-es el tema central de mi tesis doctoral. 


\section{EL ORFEÓ CATALÀ Y LA FESTIVIDAD DE SANT JORDI}

Para el tema que nos ocupa, es importante señalar que en el cambio de siglo -en el contexto posterior a la pérdida de la guerra de Cuba (1895-1898)-comenzaron a desarrollarse los nacionalismos y regionalismos ibéricos en España. Aunque en general las respuestas frente al llamado "desastre colonial" fueron de patriotismo, en Cataluña las reacciones fueron más encontradas, ya que las beneficiosas relaciones comerciales que la burguesía catalana mantenía con Cuba, Puerto Rico y Filipinas terminaron con el fin del conflicto. ${ }^{48} \mathrm{El}$ surgimiento de estos nacionalismos subestatales tendría enormes implicaciones en la vida interna de la colectividad española residente en la ciudad de México, así como en la catalana en particular. A lo anterior se sumaba el crecimiento sostenido de la inmigración española, desde el último lustro del siglo xIx y durante la primera década del xx -como ya se vio-, lo cual favoreció la concentración de individuos procedentes de las mismas regiones peninsulares. Así, por un lado, los inmigrantes catalanes llegaban de un espacio que en esos años se encontraba en pleno proceso de fortalecimiento de su identidad regional, mientras que, por otro, gran parte de la población provenía del mundo del trabajo fabril y urbano, debido al impulso industrial que experimentó Cataluña en esos años y el consecuente crecimiento de sus principales ciudades, sobre todo Barcelona.

En el contexto y la coyuntura anteriores cabe destacar la fundación de un Centro Catalán en la ciudad de México, en agosto de 1905, de carácter muy efímero y que, según Miquel Martí, se deshizo a causa de las discusiones políticas a favor o en contra de Alejandro Lerroux (Martí, 1989, pp.

${ }^{48}$ De manera paralela, el excapitán general de Cuba y Filipinas, general Polavieja, articuló un programa de regeneración nacional con propuestas de autonomía para Cataluña, sobre todo en el ámbito económico y del derecho civil, que logró la adhesión de importantes industriales y comerciantes catalanes. Desde entonces, el retroceso de los partidos de ámbito nacional en Cataluña se acentuaría y el catalanismo cobraría cada vez más fuerza. No obstante, es necesario señalar que el catalanismo burgués fue sólo una de las dos líneas constitutivas del catalanismo, aunque esta vertiente ganó fuerza a partir de la década de 1890. Sin embargo, durante el siglo xIX el catalanismo fue mayoritariamente de izquierdas y estuvo imbricado con la tradición del republicanismo federal y los sectores populares. Para nuestro objeto de estudio, no hemos observado manifestaciones específicas del catalanismo de izquierdas en el contexto mexicano. Quizá también porque esta investigación comienza en 1887, cuando se considera que la hegemonía entre las dos vertientes del catalanismo pasó al bando conservador (Capdeferro, 1990, pp. 488-491; Granja, Beramendi y Anguera, 2001, pp. 72-73; Gabriel, 2000, pp. 73-76). 
73-76). ${ }^{49}$ La conformación de la junta directiva de esta sociedad, al igual que su equivalente de años anteriores cuya acción se vio frustrada -La Colla de Montserrat-estaba formada por jóvenes hombres de negocios: Ignacio Cinca (presidente), dueño de la fábrica de cerillos La Unión; Joaquín Palau (vicepresidente), exgerente del Banco de Guanajuato, y Maximiliano de Lassé (tesorero), director gerente de la fábrica de bonetería La Perfeccionada, entre otros individuos. ${ }^{50} \mathrm{Al}$ contrario que el Centro Catalán, el origen del Orfeó Català (1906) -fundado tras la desaparición del anterior- se relaciona con unos obreros provenientes de San Francisco (California), adonde habían ido para la reconstrucción de la ciudad tras el terremoto que la había destruido aquel año. A su vuelta se establecieron en la capital mexicana, misma que se encontraba en pleno auge en la construcción de edificios públicos. Según Martí, entre los primeros socios fundadores se encontraban varios maestros de obra, así como un grupo de intelectuales, artistas y músicos. El primer presidente del Orfeó Català fue Enrique Botey, ${ }^{51}$ gerente de la Compañía de Taxímetros, una de las primeras empresas de taxis. ${ }^{52}$ Entre otros socios fundadores observamos la presencia del músico Guillermo Ferrer y Clavé, ${ }^{53}$ quien sería el primer maestro de la masa coral del Orfeó, así como del comerciante e industrial Juan Planas y Figueras. ${ }^{54}$ Los datos anteriores reflejan a un sector

${ }^{49}$ Las discusiones en torno a Lerroux se enmarcan en la fundación de la Unión Republicana (1903), la cual se creó con el objetivo de establecer una fuerza republicana unida, sólida, democrática y regeneradora. La Unión integraba sectores muy diversos que, a grandes rasgos, conformaban dos corrientes internas: los radicales y los reformistas, dos maneras distintas de orientar la modernización de la política española. Los radicales fueron seguidores de Lerroux, quien abogaba por un progresismo popular, inscrito en una política obrerista. Los reformistas estaban conformados por sectores de la burguesía que querían una reforma del Estado y la sociedad, pero sin cuestionar sus derechos jurídicos y económicos. Lerroux provenía de la tradición de la izquierda catalana -republicana, federal y progresista-, la cual había sido hegemónica durante el siglo XIX, respecto del catalanismo conservador (Gabriel, 2000, pp. 76-79; Suárez, 1998, pp. 167-171).

50 "El Centro Catalán", El Correo Español, 28 de agosto de 1905; Guía general descriptiva de la República Mexicana, 1899, p. 196; "Notas comerciales", La Gaceta Comercial, 5 de septiembre de 1900; La Semana Mercantil, 23 de febrero de 1903, p. 122; "Los dos incendios de La Perfeccionada”, Iberia, 12 de junio de 1902.

${ }^{51}$ Enrique Botey nació en 1877 en El Masnou y emigró a México en 1898. En Cataluña se había desempeñado como comerciante (Muriá, 1996, p. 71).

52 "Los cargos contra la Cía. de taxímetros", El Diario del Hogar, 23 de octubre de 1911.

${ }^{53}$ Nieto del músico José Anselmo Clavé. En 1901 llegó a México como miembro del Octeto Español y después se integró en el Quinteto Jordà-Rocabruna (Muría, 1996, p. 157).

${ }^{54}$ Además, otros socios fundadores, que no hemos podido dirimir a qué se dedicaban fueron: José Balcells (vicepresidente), Jaime Bofill, José Subirachs, Juan Costa, Ricardo Estruch, 
representativo de los catalanes residentes en la ciudad de México durante los primeros años del siglo xx: propietarios de industrias, dueños de negocios, trabajadores de la construcción, artistas e intelectuales ${ }^{55}$ (véase cuadro 2).

Con la fundación del Orfeó Català, la colectividad de este origen contó con la existencia de un espacio asociativo propio, cuya singularidad fue su masa coral, lo que articuló la identidad catalana con base en el elemento musical. Lo anterior otorgó al Orfeó un amplio reconocimiento social, entre otros aspectos debido a la inexistencia de otro Orfeón en la capital mexicana, lo que facilitó el establecimiento de puentes con otras asociaciones mediante la participación en diversas celebraciones y festividades sociales. Sin embargo, es importante señalar que el Orfeó no surgió en oposición al grupo de españoles reunidos en torno a la Junta de Covadonga, pues la asociación era partícipe de la fiesta anual que desde 1893 se organizaba en el Tívoli del Elíseo y que reunía a los españoles residentes en la capital. El Orfeó creó su propia comisión de fiestas, cuya celebración por antonomasia era la festividad de Sant Jordi y del Corpus, la cual tenía lugar el 11 de septiembre ${ }^{56}$-tres días después que la Covadonga-y que sustituía al antiguo festejo de Montserrat. La fiesta de Sant Jordi se caracterizó por la celebración de una misa en la iglesia de San Hipólito, seguido de un baile de gala y, en ocasiones, una kermesse en el teatro Tívoli.

Una rápida mirada a un aspecto de la celebración de Sant Jordi resulta ilustrativa de la heterogeneidad ideológica de los miembros que componían la colectividad catalana, pues la celebración de la misa se caracterizaba tanto por el canto de la Marcha Real (himno oficial de España) durante el Sanctus, como por Els Segadors (himno oficial de Cataluña, desde 1899) al final del oficio. ${ }^{57} \mathrm{La}$ adhesión al espacio más amplio de la monarquía española, por un

Pedro Altés, José Comas, Aurelio Marín, Antonio Balcells, Juan Estefa, Garriga, Claudio Maleras, Ferran, Antonio Simó, Enrique Sunyer, Francisco Serra, Enrique Moreno, Miguel Codina, Rovira, Trias, Sabater, Riba, Febrer, Luis Ponsa y Enrique Batlle (Martí, 1989, pp. 11-13).

${ }^{55}$ Lo anterior no es óbice para que el perfil social de los catalanes residentes en la ciudad de México presente una mayor complejidad, como de hecho se muestra con el análisis de los primeros miembros y fundadores del Orfeó Català, quienes eran obreros de la construcción, tal y como se indica en la página anterior.

${ }^{56}$ Dato aportado por Miquel Marti i Soler (1989, p. 19) en su libro. No obstante, en los primeros años de celebración de la fiesta, esta tuvo lugar en el mes de abril, como acostumbraba a celebrarse en Cataluña ( 23 de abril), tal y como puede observarse en referencias más adelante.

${ }^{57}$ Els Segadors hace referencia a los hechos del "Corpus de sangre", una revuelta en la que participaron alrededor de 1000 segadores el 7 de junio de 1640, día de Corpus Christi. El que en estas fechas se conformó como himno de Cataluña modificó parte de la letra de esta canción, lo que fue realizado por Emilio Guanyavents, para que estuviera en consonancia con elementos 


\section{Cuadro 2. Catalanes destacados de la ciudad de México a comienzos del siglo xx}

Nombre

Ignacio Cinca

Joaquín Palau

Maximiliano

de Lassé

Enrique Botey

José Subirachs

Guillermo Ferre

y Clavé

Juan Planas y

Figueras $^{\mathrm{a}}$
Actividad

Negocio
Propietario de industria La Unión, fábrica de cerillos

Banca y crédito

Gerente

Gerente

Dueño de negocio

Músico

Comerciante e

industrial
Gerente del Banco de Guanajuato

La Perfeccionada, fábrica de bonetería

Cía. de Taxímetros, empresa de taxis

La Mallorquina, pastelería

Casa Planas, fabricación y comercialización de velas, quitasoles y toldos

a Nacido en Vilanova de la Muga (1882), llegó a México en 1896. Además de su negocio, también trabajó en la Cía. Internacional de Toldos y Cortinas (Muriá, 1996, p. 285).

Fuente: elaboración propia a partir de su asociacionismo en torno al Centro Catalán y el Orfeó Català. Sólo se incluyen aquellos individuos que ha sido posible identificar por su ramo de actividad y negocio.

lado, o la defensa de la identidad catalana de manera separada de la anterior, por otro, constituían una fuente de conflicto permanente dentro de la asociación, lo que llegó a causar la dimisión de su segundo presidente, Salvador Gibert, en 1907 (Martí, 1989, pp. 19-20). Estas tiranteces se perciben también en la carta que envió en 1908 el ministro de España en México, -Bernardo Jacinto de Cólogan-al gobierno español, informando que había sido invitado

de la identidad catalana, en el contexto de la eclosión de los nacionalismos periféricos. Por su parte, el 11 de septiembre era la fecha de la rendición de Barcelona ante las tropas borbónicas durante la guerra de Sucesión. El final de este conflicto, marcado por la victoria de Felipe V, quien adoptó un modelo de nacionalización excluyente y conservador, supuso para Cataluña la abolición de las instituciones catalanas mediante los Decretos de Nueva Planta (1716) y, más tarde, la imposición de la división provincial (1833). Según Agustí Colomines (2005, pp. 516-517), estos aspectos resultan centrales para comprender el desarrollo del catalanismo. La festividad de Sant Jordi nunca correspondió en Cataluña con el 11 de septiembre, sino con el 23 de abril, por lo que la celebración en México era muy ecléctica, sumando símbolos catalanes de diversos orígenes y procedencias. 
al festejo de Sant Jordi. En la misiva, el diplomático afirmaba que Enrique Botey y Juan Planas, quienes lo habían convocado a que asistiera a la fiesta,

se mostraron a la verdad algo tímidos y cohibidos al prevenirme que el sermón sería en catalán, y al apresurarse a señalarme que el "Gloria a España" de Clavé figuraba en primera línea al lado de "Els Segadors", cuya letra, me decían, nada molesto tiene para España. Pronto los tranquilicé: supongo que a Los Segadores, contesté, les hace falta que se repitan lo bastante para que aún para los suspicaces resulte ineficaz o embotada toda malévola interpretación [...]; puede pues el Orfeón, por lo que a mí hace, cantarlo cuanto guste, y aún tengo curiosidad de conocerlo, por no haberlo oído nunca, si bien juzgo muy del caso el "Gloria a España". En cuanto al catalán, no pude olvidar las felices y oportunas palabras de S. M. el Rey al Alcalde de Barcelona, y les manifesté que, comprendiendo muy bien que los catalanes tuvieren cariño a su lengua nativa y del hogar, y más aun habiéndola cultivado literariamente, creía también que no sólo necesitaban el español para comunicarse con el resto de España, sino que nadie mejor que ellos mismos podían comprobar aquí prácticamente que nuestro idioma nacional era el único que ponía a Cataluña en condiciones de tener contacto y trato mundial. Correspondiendo a sus manifestaciones, les dije asimismo, que bien comprendía que al dirigirse al Ministro de España, no podían menos de hacerlo en el concepto de tan españoles como cualesquiera otros; $y$ aludiendo a las vivas discusiones actuales de por allá, les manifesté que tan comprensible me parecía la aspiración a una mayor expansión de la personalidad local, como respetable el temor opuesto a [ilegible] el vínculo nacional. ${ }^{58}$

Por otro lado, en 1907 se había fundado la Agrupació Catalanista, adherida a L'Unió Catalanista ${ }^{59} \mathrm{y}$ formada por algunos socios fundadores del Orfeó Català, quienes habían sido expulsados por oponerse a que figurara la bandera española en los festejos. El día de Sant Jordi de 1908 la Agrupació

${ }^{58}$ Noticia relativa a la celebración de la fiesta de San Jorge por los catalanes. 22 de abril de 1908. Caja 269, fs. 4-7. Archivo Histórico de la Embajada de España en México (en adelante AHEEM), México.

${ }^{59}$ L'Unió Catalanista (1891) fue una confederación de entidades catalanistas de muy diverso signo. Se enmarca en la tradición conservadora del catalanismo. Desde L'Unió se crearon las famosas "Bases de Manresa", un texto que rompía con la tradición ideológica que ligaba el catalanismo con el federalismo de 1873 (Gabriel, 2000, p. 76). 
izó la bandera catalana entre dos enseñas mexicanas, eludiendo la española. El ministro de España se comunicó con Ignacio Mariscal -ministro de Relaciones Exteriores- para que se retirasen las insignias catalanas. ${ }^{60} \mathrm{Al}$ respecto, los miembros de la Agrupació Catalanista fueron citados por el Ministerio de Relaciones Exteriores e informados de que el gobierno mexicano "no consentiría ofensas o demostraciones molestas a España y a su Representación". Asimismo, el antedicho Ministerio informaba a Cólogan que, en lo sucesivo, podría volver a actuar como mediador en asuntos similares. ${ }^{61}$ Lo anterior demuestra no sólo la diversidad ideológica e identitaria que existía dentro de la colonia catalana, sino también la inquietud con que la progresiva emergencia de una conciencia nacionalista fue abordada por parte de la Legación Española en el país; como indica el hecho de que Cólogan tuviese que recurrir al gobierno mexicano para imponer su autoridad entre los propios españoles -en este caso catalanes. ${ }^{62}$

La relación del grupo de catalanes reunidos en el Orfeó Català con los individuos del Casino Español era ambigua debido a diversos factores. Al respecto, cabe señalar que en 1908 estalló entre los españoles de la ciudad de México el problema del regionalismo, debido a la existencia de cuatro centros regionales que se habían fundado en los últimos años -Centro Vasco, Centro Gallego, Agrupación Aragonesa y Orfeó Català- y el rechazo que a su creación mostraron los individuos del Casino Español, quienes deseaban que los españoles se asociasen en una sola institución. Así, la Junta Española de Covadonga, formada por los individuos del Casino Español, organizó un banquete para proponer la integración en una "Casa de España" de los centros anteriores, todos los cuales se manifestaron contrarios a la propuesta (Martí, 1989, p. 22). En los días subsiguientes, Enrique Botey publicó una serie de cartas en El Correo Español dirigidas a Emilio Segura -artífice de la propuesta de la "Casa de España"-, donde lo acusaba de desconocer "las aspiraciones regionalistas y nacionalistas catalanas", así como manifestaba el "absurdo del uniformismo en España" y defendía el derecho a la autonomía como forma de organización política en Cataluña. ${ }^{63}$ Además, en 1906 Enrique Botey había

\footnotetext{
${ }^{60}$ Sobre un alarde frustrado con la bandera catalana. 25 de abril de 1908. Caja 269, fs. 4-8. AHeem, México.

${ }^{61}$ Sobre incidentes catalanistas. 11 de mayo de 1908. Caja 269, fs. 4-10. AHEEm, México.

${ }^{62}$ El Archivo de la Legación Española en México no arroja mayor documentación que la referida en este artículo respecto de la colonia catalana en la ciudad de México.

63 “Campo neutral”, El Correo Español, 16, 21, 23, 29 y 30 de octubre de 1908.
} 
impulsado la primera publicación en catalán de la ciudad de México, Brancas Catalanas, un periódico mensual ilustrado destinado a noticias de literatura, arte y actualidad, del cual no se han encontrado ejemplares (Surroca, 2000, p. 17). En suma, la fundación del Centro Catalán y del Orfeó Català, la publicación de Brancas Catalanas, el alegato de Enrique Botey contra la "Casa de España" y la existencia, aunque efímera, de la Agrupació Catalanista muestran que, a finales de la primera década del siglo $\mathrm{xx}$, la conformación ideológica de la colonia catalana era muy diferente a la de 20 años atrás, durante la celebración de las fiestas de Montserrat.

\section{CONCLUSIONES}

La festividad de Montserrat fue la primera celebración específicamente catalana de la ciudad de México en el siglo xix. Organizada e instituida por catalanes, tuvo como objetivo la articulación de la identidad española en torno a la creciente industrialización, urbanización y progreso que experimentaba esta región nororiental de la península. En este sentido, era protagonizada por los industriales y empresarios de este origen llegados a la ciudad de México en los años anteriores y, por tanto, era expresión de un catalanismo de tipo conservador y burgués, alejado de las reivindicaciones de carácter popular, obrero o federalista. La festividad de Montserrat se caracterizó, a lo largo de los seis años que existió (1887-1892), por una misa en la iglesia de San Hipólito, seguido de un banquete en la casa del industrial catalán Laureano Salazar y, en los últimos años, de un convite en el lujoso Tívoli del Elíseo. La asistencia al festejo estaba abierta tanto al conjunto de españoles como a la sociedad mexicana y el protagonismo de los acaudalados individuos del Casino Español resultaba incuestionable, así como su interés por vincularse con la elite política porfiriana, en pleno proceso de conformación de la Cámara Española de Comercio en el país. Sin embargo, en la cima de su éxito, Montserrat fue sustituida por la fiesta de Covadonga, la cual se convirtió en la celebración por excelencia de los españoles en México.

La fundación del Orfeó Català y los festejos de Sant Jordi permitieron la reorganización de la identidad catalana y la reunión de catalanes a partir de 1906. La conformación social e ideológica de sus miembros era más heterogénea que la de los últimos años del siglo xIX, pues la protagonizaron trabajadores urbanos, intelectuales, artistas y músicos, así como propietarios de 
industrias y dueños de negocios. En lo que respecta a la orientación política, el Orfeó Català integraba en su seno prosélitos de todas las tendencias, pero resultaban muy visibles los partidarios de la autonomía de Cataluña, como muestra la inclinación hacia esta opción de su primer presidente, Enrique Botey.

Finalmente, la presencia del Casino Español en ambos momentos -la celebración de Montserrat y la fundación del Orfeó Català- resulta reseñable, aunque de maneras diferentes. A fines del siglo xIX, algunos individuos del Casino Español estuvieron interesados en articular la identidad catalana como el súmmum de una España progresista. Sin embargo, la fiesta de Montserrat alcanzó en pocos años una gran visibilidad y comenzó a sugerirse la posibilidad de crear una institución que, separada del Casino Español, articulase la reunión de catalanes. Lo anterior fue vetado por los miembros de este último, así como por la representación oficial española en el país, a través del encargado de Negocios. La propuesta de Laureano Salazar de fundar una Colla de Montserrat fue en realidad el antecedente del Orfeó Català, mismo que también trató de ser integrado -junto con otras asociaciones regionales- en una Casa de España, la cual estaría controlada por los miembros del Casino Español. Sin embargo, la proposición anterior no continuó adelante.

\section{LISTA DE REFERENCIAS}

Arcelus, P. (2001). Presencia de Navarra en México, 1870-1950. Pamplona: Gobierno de Navarra.

Balcells, A. (1977). Cataluña contemporánea. Madrid: Siglo XXI.

Canal, J. (2015). Historia mínima de Cataluña. México: El Colegio de México.

Cano, A. (2009). Historia de la Cámara Española de Comercio en México. México:

Cámara Española de Comercio.

Capdeferro, M. (1990). Otra historia de Cataluña. Barcelona: Acervo.

Colomines, A. (2005). Cataluña en la España contemporánea. Interpretaciones sobre la identidad nacional. En F. Colom (ed.), Relatos de nación: la construcción de las identidades nacionales en el mundo hispánico (pp. 507-530). Madrid-Frankfurt: Iberoamericana-Vervuert, vol. I.

Commercial directory of the American Republics, vol. II (1898). Washington: Government Printing Office.

Domínguez, R. y Cerutti, M. (2006). De la colonia a la globalización. Empresarios cántabros en México. Santander: Servicio de Publicaciones de la Universidad de Cantabria. 
Gabriel, P. (2000). Las bases políticas e ideológicas del catalanismo de izquierdas del siglo xx. Espacio, Tiempo y Forma, 13, 73-103. DoI: https://doi.org/10.5944/ etfv.13.2000.3030

Garner, P. (2003). Porfirio Díaz. Del héroe al dictador: una biografía política. México: Planeta.

Garritz, A. (1996-1999). Los vascos en las regiones de México, siglos XVI a XX. México: UNAM.

Garritz, A. (2008). Aportaciones e integración de los vascos a la sociedad mexicana en los siglos XIX-XXI. México: UNAM.

Garritz, A. y Sanchiz, J. (2003). Euskal Etxea de la Ciudad de México. Vitoria: Servicio Central de Publicaciones del Gobierno Vasco.

Gil, A. (2015). Inmigración y retorno. Españoles en la ciudad de México, 1900-1936. Madrid: Instituto de Estudios Latinoamericanos-Universidad de Alcalá de Henares y Marcial Pons.

González, A. (2009). Asturias y los asturianos en México. Colombres: Fundación Archivo de Indianos.

Granja, J. L., Beramendi, J. y Anguera, P. (2001). La España de los nacionalismos y las autonomías. Madrid: Síntesis.

Guía general descriptiva de la república mexicana (1899). México: Ramón de S. N. Araluce. Gutiérrez, A. (1999). Semblanzas de españoles destacados. En C. E. Lida (comp.), España y el imperio de Maximiliano: finanzas, diplomacia, cultura e inmigración (pp. 297-338). Madrid: Alianza América.

Gutiérrez, A. (2004). Casino Español de México: 140 años de historia. México: Editorial Porrúa, 2004.

Gutiérrez, M. M. (2016). La Batalla de Covadonga en México. Imaginarios en torno a la reconquista (1889-1900). Estudios de Historia Moderna y Contemporánea de México, 51, 37-52. Dor: https://doi.org/10.1016/j.ehmcm.2016.03.002

Gutiérrez, M. M. (2019). Republicanos federales en el periodismo español de la ciudad de México durante la década de 1880. Revista Internacional de Historia de la Comunicación, 12, 305-326. DoI: http://dx.doi.org/10.12795/RiHC.2019.i12.15

Herrera, A. L. (1998). Una elite dentro de la elite: el Casino Español de México entre el porfiriato y la revolución (1875-1915). Secuencia, 42, 177-205. Dor: https://doi. org/10.18234/secuencia.v0i42.629

Herrero, C. (2004). Los empresarios mexicanos de origen vasco y el desarrollo del capitalismo en México 1880-1950. México: Universidad Autónoma Metropolitana.

Jarquín, M. T. (1981). La población española en la ciudad de México según el Padrón General de 1882. En C. E. Lida (coord.), Tres aspectos de la presencia española en 
México durante el porfiriato. Relaciones económicas, comerciantes y población (pp. 178225). México: El Colegio de México.

Lida, C. E. (1994). El perfil de una inmigración: 1821-1939. En C. E. Lida (comp.), Una inmigración privilegiada. Comerciantes, empresarios y profesionales españoles en México (pp. 25-51). Madrid: Alianza Editorial.

Lida, C. E. (2009). Caleidoscopio del exilio: actores, memoria, identidades. México: El Colegio de México.

MacGregor, J. (1992). México y España: del porfiriato a la revolución. México: Instituto Nacional de Estudios Históricos de la Revolución Mexicana.

Martí, M. (1989). L'Orfeó Català de Mèxic (1906-1986). Barcelona: Curial.

Moreno, J. (2007). La otra España. Empresas y empresarios españoles en la ciudad de México durante la revolución. América Latina en la Historia Económica, 27(1), 111156. DoI: https://doi.org/10.18232/alhe.v14i1.313

Muriá, J. M. (coord.) (1996). Diccionario de los catalanes de México. Zapopan/Barcelona: El Colegio de Jalisco/Generalitat de Catalunya.

Peregrina, A. (2013). Introducción. En J. M. Muriá, A. Peregrina y F. Velázquez (coords.), Huellas de catalanes en México (pp.7-12). México: Instituto Nacional de Antropología e Historia.

Pérez, M. (2013). Catalanes en México durante las primeras décadas del siglo xx: consideraciones para su estudio. En J. M. Muriá, A. Peregrina y F. Velázquez (coords.), Huellas de catalanes en México (pp. 87-110). México: Instituto Nacional de Antropología e Historia.

Pérez, P. (1981). Algunas hipótesis de trabajo sobre la inmigración española a México: los comerciantes. En C. E. Lida (coord.), Tres aspectos de la presencia española en México durante el porfiriato. Relaciones económicas, comerciantes y población (pp. 101173). México: El Colegio de México.

Pérez, S. (1999). Los españoles de la ciudad de México durante el segundo imperio. En C. E. Lida (coord.), España y el imperio de Maximiliano: finanzas, diplomacia, cultura e inmigración (pp. 261-293). Madrid: Alianza América.

Pi-Suñer, A. y Sánchez, A. (2001). Una historia de encuentros y desencuentros: México y España en el siglo XIX. México: Secretaría de Relaciones Internacionales.

Pla, D. (1999). Els exiliats catalans: un estudio de la emigración republicana española en México. México: Instituto Nacional de Antropología e Historia/Orfeó Català de México.

Pla, D. (2003). El aroma del recuerdo. México: Plaza y Valdés/Consejo Nacional para la Cultura y las Artes/Instituto Nacional de Antropología e Historia. 
Ríos, M. F. (2005). De la Restauración a la Reconquista: la construcción de un mito nacional (Una revisión historiográfica. Siglos XVI-XIX). La España Medieval, 28, 379-414. Recuperado de https://revistas.ucm.es/index.php/ELEM/article/view/ ELEM0505110379A

Ríos, M. F. (2011). La Reconquista. Una construcción historiográfica (siglos XVI-XIX). Madrid-México: Marcial Pons/Universidad Nacional Autónoma de México.

Ruiz, S. (2002). Emigración riojana a México (siglo xx). Logroño: Gobierno de La Rioja/ Instituto de Estudios Riojanos.

Salazar, D. (2010). Las cuentas de los sueños. La presencia extranjera en México a través de las estadísticas nacionales, 1880-1914. México: Instituto Nacional de Migración/ Conaculta/Secretaría de Gobernación-DGE Ediciones.

Sánchez, A. (1999). La normalización de las relaciones entre España y México durante el porfiriato (1876-1910). Historia Mexicana, 48(4), 1999, 731-765. Recuperado de https://historiamexicana.colmex.mx/index.php/RHM/article/view/1266

Sánchez, A. y Pérez, P. (2015). Historia de las relaciones entre España y México, 1821-2014. Madrid: Marcial Pons.

Sepúlveda, I. (2005). El sueño de la madre patria: hispanoamericanismo y nacionalismo. Madrid: Fundación Carolina/Centro de Estudios Hispánicos e Iberoamericanos/ Marcial Pons Historia.

Suárez, M. (1998). El republicanismo español tras la crisis de fin de siglo (1898-1914). Cuadernos de Historia Contemporánea, 20, 165-189. Recuperado de https://revistas. ucm.es/index.php/CHCO/article/view/CHCO9898110165A

Surroca, R. (2000). Prensa catalana en México (1906-1982). México-Barcelona: El Colegio de Jalisco/Generalitat de Catalunya.

Tenorio, M. (1998). Artilugio de la nación moderna. México en las exposiciones universales 1880-1930. México: Fondo de Cultura Económica.

Tuñón, E. (2011). Varias voces una historia: mujeres españolas exiliadas en México. México: Instituto Nacional de Antropología e Historia.

Yáñez, C. (1996). Saltar con red. La temprana emigración catalana a América, ca. 18301870. Madrid: Alianza.

\section{OTRAS FUENTES}

Aheem Archivo Histórico de la Embajada de España en México. 